\title{
Climate change research within Regional Environmental Change
}

\author{
James D. Ford ${ }^{1}$
}

Received: 5 June 2015/Accepted: 14 June 2015/Published online: 24 June 2015

(c) Springer-Verlag Berlin Heidelberg 2015

The goal of the journal Regional Environmental Change (REEC) is to publish scientific research and opinion papers that improve our understanding of the extent of environmental changes, their causes, their impacts on people, and the options for society to respond. Reflecting growth of the environmental change field, the journal has expanded rapidly in recent years, with the annual number of published articles reaching 169 in 2014, a more than fivefold increase since 2010, and more than a quarter of all 735 articles published since the journals founding in 1999. To account for this increase, the number of regular published journal issues was increased from 4 to 6 in 2013 and to 8 in 2015. I (James Ford) also joined the journal recently as joint Editor-in-Chief to work with the long-serving Wolfgang Cramer, in part to manage and cope with the everincreasing volume of submissions, but also to help further develop the interdisciplinary profile of the journal, specifically climate change content. This editorial identifies the kinds of climate change content we are looking to profile in REEC in the coming years, while also emphasizing that we continue to welcome and promote the submission of a wide variety of environmental change-focused articles.

Naturally, climate change has been a key concern of REEC in recent decades, and since the journals founding approximately half of our published articles have had a climate change focus $(n=374)$ (Fig. 1). Proportionally, climate change articles have also increased in importance over time and are the focus of a quarter of articles from 1999 to 2009 and $60 \%$ from 2010 to 2015 (Fig. 1).

James D. Ford

James.ford@mcgill.ca

1 Department of Geography, McGill University, Montreal, Canada
Already in the first 3 months of 2015, more climate change papers were published in the journal than from 1999 to 2008 combined. The impact (and breadth) of climate change articles published in REEC has increased over time and is particularly notable in the Fifth Assessment Report of Working Group II (WGII) to the Intergovernmental Panel on Climate Change (IPCC), with REEC articles cited across 26/30 chapters (Fig. 2).

The main focus of climate change articles in the journal to date has been on impacts $(n=202,54 \%)$, where studies identify and evaluate the detrimental and beneficial consequences of climate change on natural and human systems. This focus is intentional: Indeed, we routinely advise authors of papers dealing with climate change processes to submit to expert climatological journals instead. Modeling future impacts in particular has been an important focus in this work, with studies reporting from a diversity of sectors and geographic regions. Vulnerability is the focus of $22 \%(n=82)$ of climate change-focused articles, with emphasis on the biophysical and human factors which affect sensitivity, adaptive capacity, and resilience to change. These articles began to appear in the journal in the last years of the 2000s, with peaks in 2010 and 2011. A limited number of adaptation studies were published in the first decade of the journal's existence, but have emerged as an important focus since 2010, forming $24 \%$ of all climate change content $(n=90)$; this mirror trends in the adaptation literature in general (Berrang-Ford et al. 2011).

As the climate change field continues to grow, we expect climate change-focused submissions to further rise, although-like other journals-we will of course always favor quality before quantity. Our interest will be to publish a diversity of studies in the field, emphasizing the interdisciplinary focus of cutting-edge research. We focus 


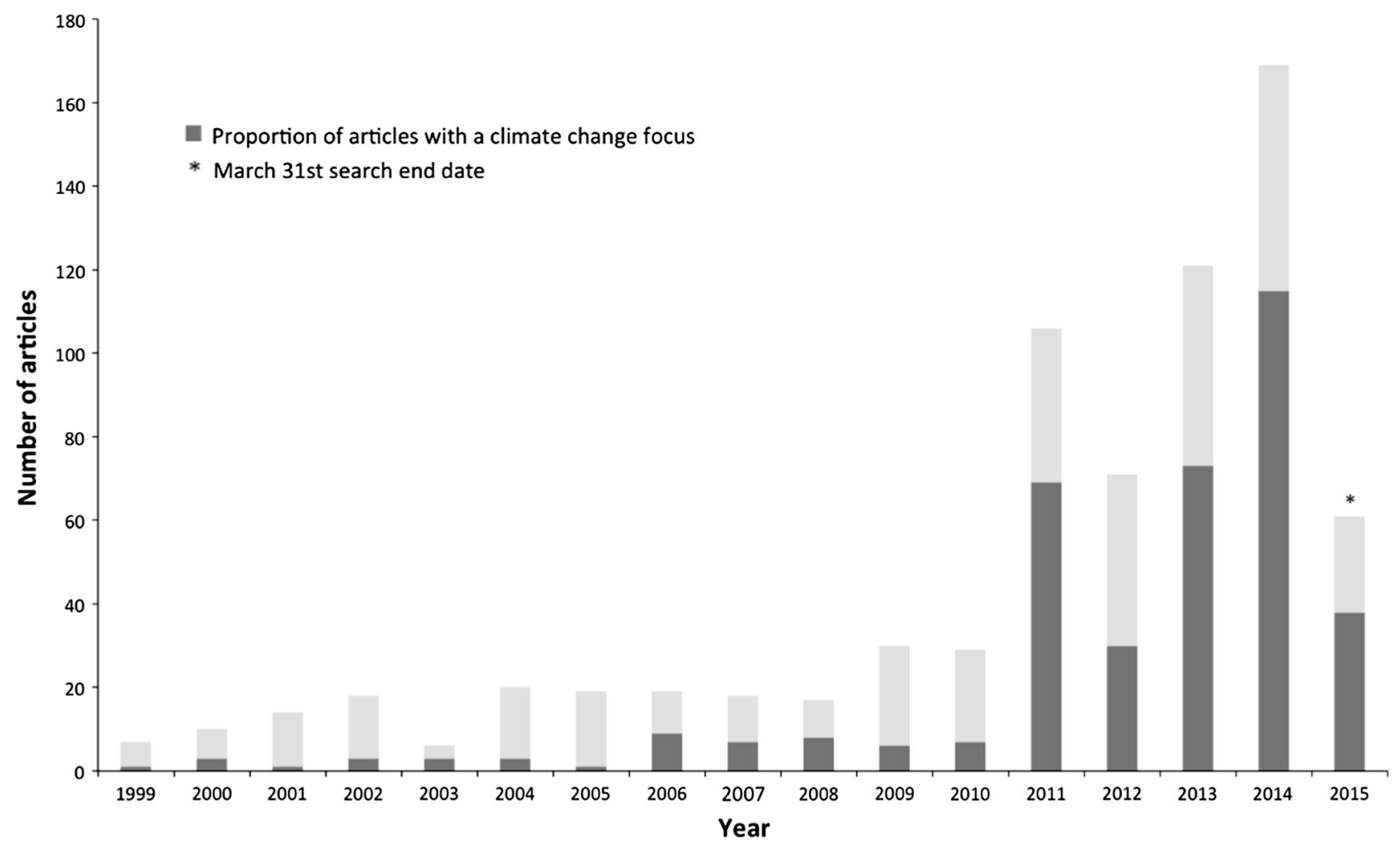

Fig. 1 Climatic change-focused articles within Regional Environmental Change

\section{IPCC AR5 WGII Report}

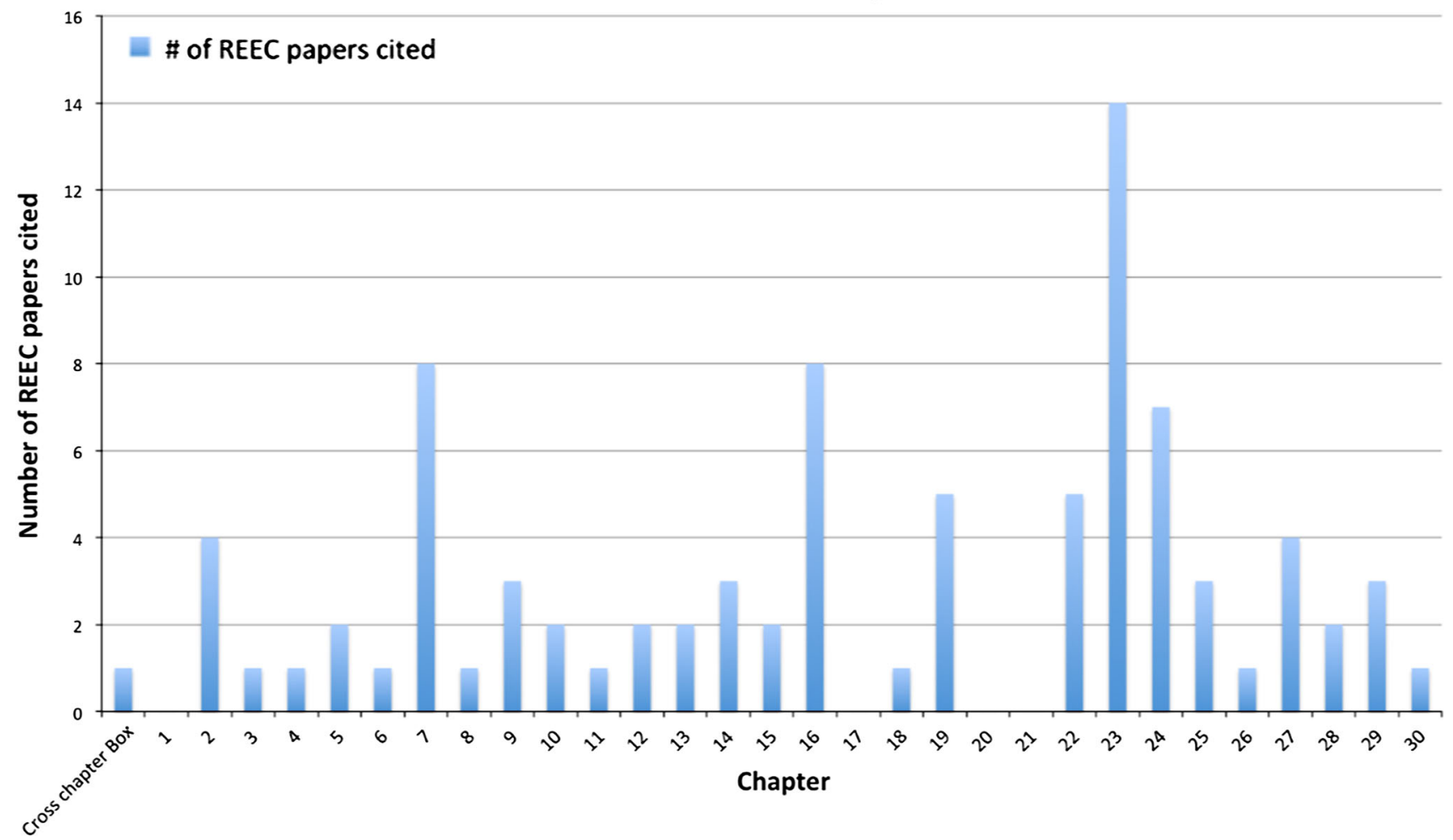

Fig. 2 Number of REEC articles cited in specific chapters of WGII of the IPCC Fifth Assessment Report 
on studies made at the regional level (see Cramer 2002), while ensuring that articles make contributions beyond the specific case being studied. Emphasis on human dimensions is a key criteria by which we assess relevance to the journal, be it examining human causation (e.g., factors creating vulnerability), impacts on humans, or human responses. However, with increasing submission rates, we will necessarily have to be more selective in the papers we send to review, choosing articles that not only present excellent science, but also make important theoretical, methodological, and/or empirical contributions. Key areas of interest moving forward include:

1. Impacts assessment As demonstrated by recent IPCC assessments, the climate is changing, impacts are documented from continents and oceans globally, and some degree of future change is inevitable, even with substantially enhanced mitigation efforts. Research is needed to identify and characterize future impacts under a range of potential scenarios, and REEC particularly welcomes studies from high-risk locations and populations (e.g., megacities and indigenous populations), understudied regions, neglected sectors (e.g., industry and transportation), and risks (e.g., health), and those that develop novel impact assessment methodologies. Over the last decade, we have published many studies documenting perceptions of change and characterizing observed impacts, and while important areas of study, we will be more selective in accepting such work given the well-established knowledge base in this area.

2. Vulnerability Vulnerability studies seek to identify and characterize who is vulnerable, to what stresses, and why, paying particular attention to the interaction between human and biophysical factors that affect exposure, sensitivity, and adaptive capacity to change. A significant literature on vulnerability has emerged over the last decade, with studies published in REEC having an emphasis on developing indicators of vulnerability, quantifying vulnerability under different scenarios, and reporting on local case studies of vulnerability assessment. Moving forward, we see a need for studies that more comprehensively account for current and future drivers of vulnerability, meaningfully integrate qualitative and quantitative approaches, and capture the complex interaction of socioecological systems over multiple spatial-temporal scales. Innovative theoretical, methodological, and empirical papers are welcome, and while we strongly value case study research, such work needs to clearly articulate its broader contributions to the field. Resilience studies are also encouraged.
3. Adaptation Adaptation has emerged as a major component of climate policy across scales and is reflected in a rapidly growing body of scholarship in this field. Studies in REEC have examined the opportunities and barriers to adaptation in diverse contexts, identified adaptation options, and explored the political and ethical issues surrounding adaptation, and a recent special edition examines adaptation actions being undertaken across nations (De Souza et al. 2015). These are all areas of research that align well with the aim of REEC. In addition, we want to encourage articles that examine adaptation performance under different socioeconomic and climate scenarios, specifically how adaptation interacts with human systems in the short and long term; empirical studies that document and examine examples of adaptation; the governance of adaptation; along with research monitoring and evaluating adaptation progress.

4. Science-policy The creation of 'usable' or 'decisionorientated' science, with specific goals to inform decision-making processes, underpins much climate change research. One example for such transfer is the IPCC, which in its reports draws heavily on papers from REEC (Fig. 2)—similar impact can be expected for the Intergovernmental Science-Policy Platform on Biodiversity and Ecosystem Services (IPBES). Yet some have questioned whether research has actually improved decision making (Lemos et al. 2012), with an emerging scholarship examining how to design impacts, adaptation, and vulnerability studies to maximize their 'usability.' Few studies in REEC to date have been published in this area, and we particularly welcome work that examines the processes by which knowledge can be effectively co-produced, assesses the role science plays in decision making in various contexts, and examines the role played by institutions at the science-policy interface (e.g., boundary organizations, communities of practice, and knowledge brokers).

These areas of interest are by no means exhaustive, but give an idea of the kind of climate change content REEC is looking to profile in the coming years. We also emphasize that REEC continues to welcome non-climate change-focused articles. Original research articles will continue to be the main focus of how climate change research is communicated, alongside targeted special issues. We will also encourage more short communications which present findings of significant interest. These communications receive high review priority and after acceptance will be published in the next journal issue. Such articles may report on the findings of original research, be thought 
pieces that seek to catalyze new theoretical or methodical approaches, or be commentaries targeted at specific policy issues. Given the rapidly evolving nature of climate change research, we believe that short communications will have an important role in engaging and promoting key ideas in climate change research and policy to the scientific community and beyond.

Climate change has been identified as one of the main challenges facing humanity this century. New institutional structures are emerging to direct research and inform decision makers on the risks posed, while climate policy is becoming a central focus of policy making across scales. Scientific journals like REEC can play a major role informing such developments, profiling rigorous scientific research, and encouraging evidence-based debate. We look forward to continuing to provide this role.

\section{References}

Berrang-Ford L, Ford JD, Patterson J (2011) Are we adapting to climate change? Glob Environ Chang 21:25-33. doi:10.1016/j. gloenvcha.2010.09.012

Cramer W (2002) A new look at Regional Environmental Change considerations for the next phase of this journal. Reg Environ Chang 3:1. doi:10.1007/s10113-002-0051-2

De Souza K, Kituyi E, Harvey B, Leone M, Murali KS, Ford JD (2015) Vulnerability to climate change in three hot spots in Africa and Asia: key issues for policy-relevant adaptation and resilience-building research. Reg Environ Chang 15:747-753. doi:10.1007/s10113-015-0755-8

Lemos MC, Kirchhoff CJ, Ramprasad V (2012) Narrowing the climate information usability gap. Nat Clim Chang 2. doi:10. 1038/nclimate1614 